\title{
HOTEL IMAGE AS AN IMPORTANT PREREQUISITE FOR CREATING A COMPETITIVE ADVANTAGE
}

\section{Daliborka Blazeska, Angela Milenkovska, Marina Stojmirova}

University of Tourism and Management in Skopje,

Skopje, Macedonia
Correspondence:

Daliborka Blazeska

e-mail:

contact@utms.edu.mk

\begin{abstract}
:
Tourism and hotel industry are showing the tendency of continuous and rapid growth on a global scale. The improvement of the working process is quite remarkable, i.e. the quality of service, but also the construction of numerous new facilities, which together affect the competition in the international tourism market, where the Republic of Macedonia also gives its national tourism product. This paper pays special attention to the hotel service, as its inevitable and irreplaceable factor determining guest satisfaction. In this paper, hotel image is particularly highlighted. Building and strengthening of the hotel image becomes one of the basic strategies for the consumers achieving greater value and better positioning in the market. The key question imposes as to how to build a good image of a hotel and identify the components that affect the hotel image. This paper analyses important components that affect the hotel image. To that end, research has been performed which confirms that the hotel image is created by products of services, location, clients, atmosphere, after-sales services and promotional activities.
\end{abstract}

Keywords:

image, hotel, quality, clients, promotion.

\section{INTRODUCTION}

The business environment in which modern hotels operate is very complex. It constantly puts pressure on the hotel management requiring from them better quality of products and services, better customer service, lower price sales, environment protection, fast and timely deliveries (Singh et al., 2015). Also, globalization puts pressure on the hotels due to the intensified competition. In order to be successful in the market and attract consumers, it is necessary to approach to building key determinants that will lead to creating a good image and competitive advantage of the hotel (Barney, 1991). Whether it is about the process of purchasing products in the supermarket or the process of choosing certain type of banking, insurance or other type of service, the customer appears as a complex personality influenced by numerous factors. Image is one of the key factors that considerably affects customers when making decisions. It builds the customer's confidence and opens up a wide spectrum of possibilities for easier and more effective market approach. 
People often tend to mix the terms product image and brand. As it is well-known, image is a psychological construction while the brand is a legal-trading construction. That means that the image is defined as an identity that presents a sum of the existing ways in which the hotel identifies itself among the consumers, the audience, the shareholders etc. Image is building and is changeable because it contains the perception of the audience for the hotel. Unlike image, identity is the real picture of the hotel. Image is the experienced quality for certain hotel versus the existing real quality of the hotel. Identity is a measurable while the image is an immeasurable variable. To build a good image, it is necessary to pay special attention to the quality of services, location, clients, atmosphere, after-sales services and promotional activities (Connelly et al., 2015). All these components will make the hotel recognizable for the targeted group. Usually, the image is not only a picture or presentation of a certain product, but the consumers also participate in its creation. Their feelings (related to certain product image) are the result of previous experiences, different beliefs, judgments and opinions. So, the image includes the design of certain product or service, the quality, technical side, functionality etc.

Therefore, image can be defined as "a set of beliefs, ideas and impressions of the person regarding a certain object or institution". It is a segment of market communication and its factors are: originality, real economic propaganda, brand recognition, appropriate manifestation of the brand to the market, the role of the sales staff, service quality etc. (Gambetti \& Graffigna, 2015). In order for the hotel to succeed in the market and to achieve a competitive advantage, it is required to have a targeted group of consumers. Their behavior should be analyzed constantly to see what type of services they prefer within certain period of life, when and how they use those services and how to create a loyal customer that will bring long-term satisfactory profitability. Every hotel should thoroughly study the reactions of consumers of the targeted group and conduct the appropriate marketing activities, promotion and set appropriate sales staff and inventory and shape the infrastructure. It is required that more detailed studies observe the consumer behviour in order to initiate activities for creation of more acceptable services that will suit our target group. Appointing trained managing staff will keep the consumers in the long run, but the same staff can also attract new consumers to increase the hotel profit.

\section{METHODOLOGY}

The paper underlines the importance of certain components in building the hotel's image. We should know that the creation of the hotel image is not something that is made within a short time period, but it is rather time and money consuming. Consumers rely on the hotel image as a perceptual reality when making the final choice. That's why we need to pay attention to its creation.

The subject of this research is:

- the role and importance of creating hotel image as an important determinant of success,

- recognition of elements that affect the image of the store

- elaboration of all pre-conditions for successful appearance of the hotel in the market and achieving a competitive advantage

This paper provides tips for successful creation of positive perception for a certain hotel. Although the determinants for hotel image creation can change from one market segment to another, this paper still emphasizes the most important components which determine whether the hotel is going to be successful or not.

\section{IMAGE}

The hotel image is determined on the basis of the entire perception that the consumers have for that hotel. In fact, the image contains functional and emotional attributes. When determining the image of the hotels, it is required to take into consideration their products, service provided to customers, regular customers, location, if there is a parking space nearby, the atmosphere, the aftersales services and the type of promotional activities applied (Gambetti \& Graffigna, 2015). It is very important to take into consideration the image of the environment where the hotel is placed. The management is interested in creating the best possible image (Conejo et al., 2015). This means that the hotels need to affect the perceptions of consumers as much as possible in order to successfully attract them in the following period. If the hotel image is not good compared to the competition, it is reasonable to spend considerable amount of money to alter the opinion of the target group.

\section{THE QUALITY OF HOTEL SERVICE AS A BASIS FOR IMAGE CREATION}

In modern terms, the quality is a success factor, very important in the context of selling products and services. The availability of information at world level, the global competition and requirements and the reduced number of loyal guests, are imposing additional responsibilities to the hotel management, regarding the research of new ways for giving a quality product. Each hotel product is extremely complex, as it is a sum of 
tangible and intangible elements of the offer which are closely linked and affect the guests' pleasure. The quality of the hotel product depends not only on the quality of the object, but also on the expertise and kindness of the staff, access to the hotel, serving speed etc. That means that the quality of service is a basic factor for achieving profitability and market competitiveness.

\section{COMPONENTS FOR IMAGE CREATION}

The concrete suggestions for creation of hotel image in the Republic of Macedonia are the following:

- First, attention should be devoted to the choice of the hotel location. It should be good and visible to consumers. The entrance should be large and recognizable i.e. easy to see

- The space and functionality should also be satisfied

- The furniture and interior décor must be at the superb level. To be modern and design by superb designers

- The hotels should have a wide assortment in order to satisfy the taste of larger number of consumers

- Quality sales staff that knows well the consumers and will influence them during the purchasing process should be hired in the hotels

\section{RESEARCH}

This research was conducted on a random selection of respondents in hotels in the entire country (Republic of Macedonia) most of them being located in Skopje. The research was about the factors that affect the image of each hotel. To that end, a questionnaire with open and closed questions was designed. The beginning of the questionnaire consists of basic and demographic data, while the rest of the questions refer to the influence of the factors on the hotel image. This questionnaire was given to 500 respondents to obtain relevant data from which the appropriate conclusions can be drawn.

As to the main reasons that trigger consumers to buy or use hotel products and services of a hotel, the following results were obtained (Table 1).

Based on the results obtained from the respondents, it can be noticed that the most common reasons why the consumers decide to buy products or use services of some hotel are the quality and the location of the hotel. The quality and the location affect the decision to purchase with $30 \%$. According to the respondents, other reasons that affect consumers are the hotel appearance with $12 \%$, price with $6 \%$, promotional activities with $10 \%$, employees with $4 \%$ and customers that purchase there with $10 \%$.

The following data were obtained concerning the importance of service for the hotel staff (Table 2).

Table 1. The reasons why consumers decide to buy or use hotel products and services

\begin{tabular}{ccccccc}
\hline location & quality & price & $\begin{array}{c}\text { promotional } \\
\text { activities }\end{array}$ & employees & $\begin{array}{c}\text { hotel appear- } \\
\text { ance }\end{array}$ & customers \\
\hline $30 \%$ & $30 \%$ & $6 \%$ & $10 \%$ & $4 \%$ & $12 \%$ & $8 \%$ \\
\hline
\end{tabular}

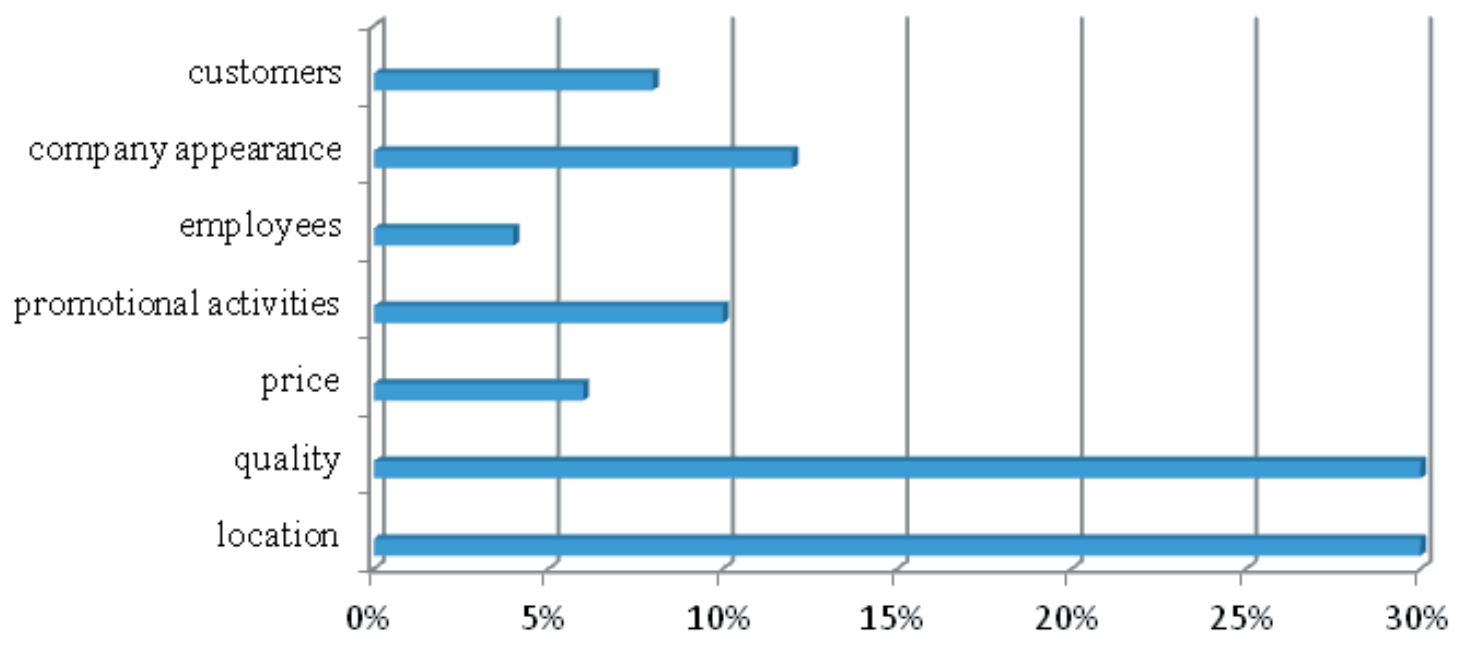

Figure 1. The reasons why the consumers decide to buy or use hotel products and services 
Table 2. The role of the hotel staff

\begin{tabular}{ccc}
\hline is not important & is important & is very important \\
\hline $16 \%$ & $32 \%$ & $52 \%$ \\
\hline
\end{tabular}

Role of the staff in the companies

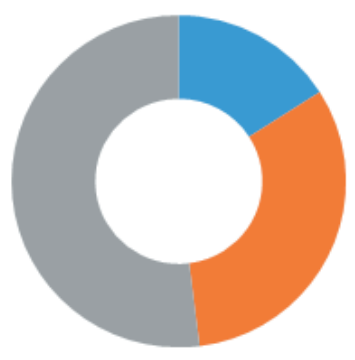

- is not important

nis important

mis very important

Figure 2. The role of the staff in the hotels

In this chart, we can see that the role of the staff is not important to $16 \%$ of the respondents, $32 \%$ of them consider it important, while 52\% consider it very important. Based on that, it can be concluded that the service provided by the personnel in the hotel is very important for customer satisfaction. Due to this fact, it is required to pay significant attention to this issue.

As regards the question of whether the promotion of hotels affects the consumers' perception and image creation, the following data were obtained (Figure 3).
The chart shows that $62 \%$ of the respondents consider that the promotion has a major impact on stimulating them to visit and the perception for creation of hotel image, $33 \%$ of them believe that the promotional activities don't influence their visits to hotels and 5\% of the respondents do not know what to say.

As regards the issue of the medium that is best for promotion, the following results were obtained (Figure 4).

According to the chart, it can be noticed that $15 \%$ of the respondents consider that the television is best for

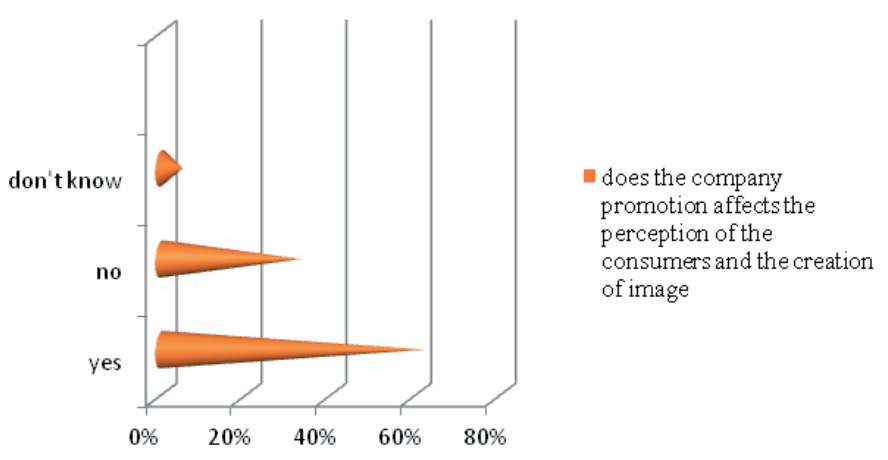

Figure 3. Influence of the promotion on the consumers' perception and image creation

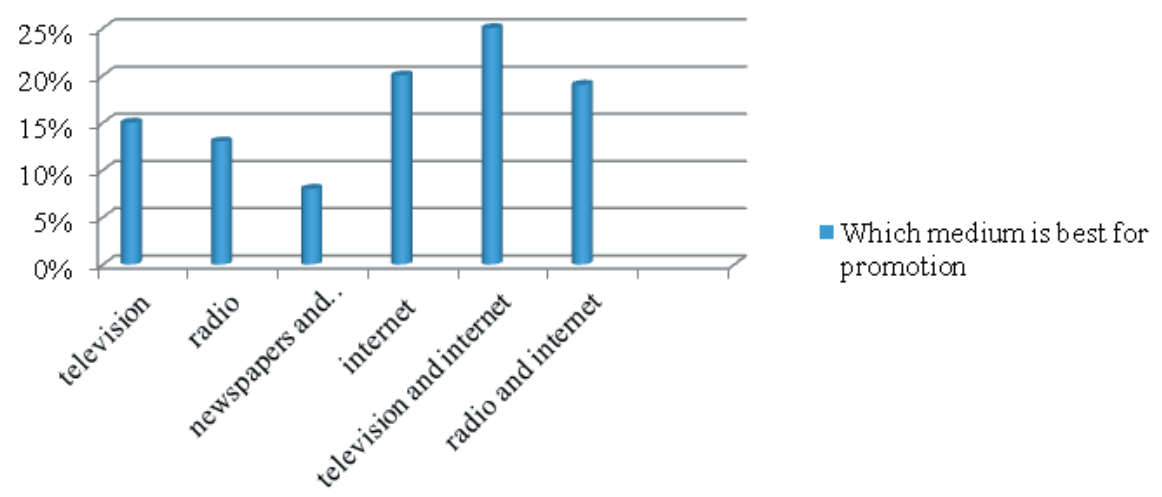

Figure 4. Which medium is the best for promotion 
promotion, $13 \%$ believe that the radio is best for promotion, $8 \%$ consider that the newspapers and magazines are best for promotion, $20 \%$ consider that the promotion will be most successful through the Internet, while $25 \%$ of them choose the combined promotion (television and internet), and $19 \%$ choose the combined promotion (radio and Internet).

\section{RESEARCH RESULTS}

According to the results of the questionnaire, the following conclusions could be drawn:

- There is interest in buying products and services of hotels that have established a positive image

- When buying a product or services, the customers make the decision because of the quality of products and services, but the location and appearance of the hotel are also very important. Promotional activities as well as the customers of the hotel also have a considerable bearing on the consumers' preference for certain hotel. Regarding the price, it is not one of the most important factors because the products and services are branded and low prices cannot be expected

- The service provided by the staff is also very important in the purchasing process

- Based on the questionnaire, we can conclude that it would be nice to take promotional activities, and the combination between the traditional and modern media is considered the most effective medium.

\section{CONCLUSION}

Macedonian customers want to visit hotels that are well-known brands. The business environment in which modern hotels operate is very complex. In order for a hotel to succeed in the market and attract potential consumers, it is necessary to approach towards building positive hotel image. We must emphasize that great part of hotels are aware of the fact that it is necessary to pay attention to significant components for building of the image such as the location, space and functionality of the hotel, atmosphere, service quality provided by the hotel staff, the quality and assortment of products, as well as promotional activities. If one hotel meets all these criteria, then it will surely have countless loyal consumers with the short-time period and achieve its goal. After some time, it will become a brand, which is what all hotels aspire to achieve. It still imposes as the main conclusion that tourists prefer an integrated quality level of the destination, which absolutely correlates with the experiences concerning modern trends of tourism development. The quality of all individual services that make the destination image means systemic action of all factors of tourism development. Nonetheless, the quality of service and employees as its immanent creators still remains the key factor towards fully gaining the trust of the guest and his/her reinstatement in the hotel/ destination.

\section{REFERENCES}

Adcock, D., Halborg, A., \& Ross, C. (2001). Marketing: principles and practice. Edinburgh: Prentice Hall.

Barney, J. (1991). Firm Resources and Sustained Competitive Advantage. Journal of Management, 17(1), 99-120.

Blythe, J. (2005). Essentials of Marketing. Edinburgh: Prentice Hall.

Bonn, M.A., Joseph, S.M., \& Dai, M. (2005). International versus Domestic Visitors: An Examination of Destination Image Perceptions. Journal of Travel Research, 43(3), 294-301. doi:10.1177/0047287504272033

Brodie,R.J., \& de Chernatony, L. (2009). Towards new conceptualizations of branding: theories of the middle range. Marketing Theory, 1(9), 95-100. doi:10.1177/1470593108100057

Conejo, F., \& Wooliscroft, B. (2015). Brands Defined as Semiotic Marketing Systems. Journal of Macromarketing, 3(35), 287-301. doi:10.1177/0276146714531147

Connelly, B.L., Crook, T.R., Combs, J.G., Ketchen, D.J., \& Aguinis, H. (2015). Competence-and IntegrityBased Trust in Interorganizational Relationships. Journal of Management. doi:10.1177/0149206315596813

Gambetti, R.C., \& Graffigna, G. (2015). Value co-creation between the 'inside' and the 'outside' of a hotel Insights from a brand community failure. Marketing Theory, 2(15), 155-178.

Kotler, P. (2003). Marketing Management. Edinburgh: Prentice Hall.

Singh, A., Saini, G.K., \& Majumdar, S. (2015). Application of Social Marketing in Social Entrepreneurship. Social Marketing Quarterly, 3(21),152-172. doi:10.1177/1524500415595208 